Talanta 57 (2002) 383-391

Talanta

ELSEVIER

Talanta $57(2002) 383-391$

www.elsevier.com/locate/talanta

\title{
Redox effects on resin extraction of herbicides from soil ${ }^{\text {is }}$
}

\author{
Alan Olness *, N.T. Basta, Jana Rinke \\ USDA, North Central Soil Conservation Research Laboratory, Agricultural Research Service, 803 Iowa Avenue, Morris, \\ MN 56267, USA
}

Received 26 September 2001; received in revised form 22 January 2002; accepted 22 January 2002

\begin{abstract}
Relative soil aeration affects the surfaces upon which pesticides adsorb and non-ionic resins offer a means of observing and evaluating this factor. A non-ionic resin extractor, developed for pesticide extraction under reducing conditions, was used to adsorb a fraction of the reversibly adsorbed (active portion) herbicides. The extractor consists of cleaned XAD-2 resin encased in a dialysis membrane composed of regenerated cellulose. Anaerobiosis was achieved by incubating soil suspensions with glucose under a $95 \% \mathrm{~N}_{2}-5 \% \mathrm{H}_{2}$ environment until the redox potential reached $-150 \mathrm{mV}$. Nine soils with a range of physical and chemical characteristics were examined for atrazine, metribuzin, and alachlor content. Amounts of atrazine, metribuzin, and alachlor extracted from soil ranged to 100, 140, and $75 \mathrm{ng} \mathrm{g}^{-1}$, respectively. Resin extractions (RE) conducted under aerobic conditions recovered about $25-50 \%$ of the pesticide extractable with conventional solid phase solvent extraction at $60{ }^{\circ} \mathrm{C}\left(\mathrm{SPE}_{60}\right)$. Under anaerobic conditions, equal amounts of atrazine were extracted with RE and $\mathrm{SPE}_{60}$. Slightly less metribuzin was recovered under anaerobic extraction with the exception of those soils lacking detectable amounts by $\mathrm{SPE}_{60}$. Larger amounts of alachlor were extracted with resins under anaerobic conditions than under aerobic conditions but the amounts were not correlated with those determined by $\mathrm{SPE}_{60}$. Large amounts of soil organic matter were solublized under anaerobiosis and smaller molecular weight material was extracted with the herbicides. The nature and amounts of co-extracted organic matter varied among soils. RE directly from soil suspensions enabled simultaneous determination of all three herbicides. (C) 2002 Published by Elsevier Science B.V.
\end{abstract}

Keywords: Anaerobiosis; Resin extraction; Soil aeration

\section{Introduction}

Herbicides have been and are being applied to $>90 \%$ of the total acreage for most crops in the US [1]. Thus, most of the soils in the US have been

In cooperation with the Oklahoma Agricultural experiment Station.

* Corresponding author. Tel.: + 1-320-589-3411; fax: + 1320-589-3787.

E-mail address: olness@morris.ars.usda.gov (A. Olness). exposed to herbicides directly or indirectly. When working with soils in the laboratory, a common assumption seems prevalent; namely, if a soil sample has not been exposed to herbicides within the past few years, that most of the previously applied material will have been degraded. Microbial degradation will leave the sample essentially free of the herbicide of interest because the half-life of the chemical is usually measured in weeks or months. However, soils in natural settings are often exposed to severe climatically effected changes. 
Soil in the field environment can be viewed as a complex of aerobic and anaerobic micro-environments (or niches). The relative sum of these niches determines momentary redox status that for well drained arable soils is usually $>400 \mathrm{mV}[2,3]$. Whenever the oxygen flow into soil is less than the oxygen demand, the number and volume of the anaerobic environments increases and the overall redox potential decreases. Such a change occurs in flooded and wetland soils where redox values of less than -100 have been recorded $[2,4,5]$.

During well-aerated conditions, herbicides adsorb on surfaces of soil organic matter, soil minerals and amorphous Fe- and Mn-oxides. Natural soil environments, including arable fields, often undergo brief episodes of flooding and anaerobiosis. During very wet periods, redox sensitive surfaces such as the amorphous $\mathrm{Fe}$ and $\mathrm{Mn}$ oxides dissolve. On re-oxidation, the Fe- and Mn-oxides reform and precipitate as amorphous complexes onto redox-stable surfaces. In the process of precipitating, these oxides trap or occlude humic substances and adsorbed organic molecules such as herbicides. Since reactive portions of occluded organic molecules are often responsible for surface adsorption, occlusion by oxide precipitates may shield them from further biochemical degradation. Extraction procedures that fail to dissolve these amorphous oxides will fail to detect that fraction of the herbicides occluded in the matrix.

The importance of the redox process on retention/release of pesticides from soils has been given little study probably because extraction of pesticides under anaerobic conditions requires more elaborate equipment and because anaerobiosis in arable soils is generally given little attention. It is a common practice to dry soil samples before extracting herbicides from them. Soil samples are rarely collected during or shortly after such events and they seem even more rarely examined using anaerobic techniques.

Recently, we described a resin device capable of extracting pesticides under a range of redox conditions [6]. The objectives of this study were to (a) compare results of extraction of pesticides from soils using the resin extractor under aerobic and anaerobic conditions and (b) compare the results in (a) with those obtained using two solvent extrac- tion methods used to determine 'total pesticide residue' in soil.

\section{Materials and methods}

\subsection{Soil sampling and characterization}

Soil samples were collected from the surface 30 $\mathrm{cm}$ depth zones from sites that had a history of herbicide application (Table 1). Organic C content was determined by a modified Mebius procedure [7,8], $\mathrm{pH}$ by glass electrode (soil: $0.01 \mathrm{M} \mathrm{CaCl}_{2}, 1$ $\mathrm{g}: 2.5 \mathrm{ml}$ ), and particle-size by the modified pipette method $[9,10]$. Cation exchange capacity (CEC) was determined using sodium saturation with correction by potentiometric chloride titration [11]. Soil samples were air-dried and ground to pass a 40-mesh sieve $(0.4 \mathrm{~mm})$.

\subsection{Herbicide extraction}

Pesticides were extracted by four methods: solvent extraction at $22{ }^{\circ} \mathrm{C}\left(\mathrm{SPE}_{22}\right)$; and $60{ }^{\circ} \mathrm{C}$ $\left(\mathrm{SPE}_{60}\right)$; resin extraction (RE) under aerobic conditions; and RE under anaerobic conditions. Pesticides were extracted by using a modification of the procedure of Basta and Olness [6]. Non-polar XAD-2 resin, (20 to 50 mesh cleaned with methanol and deionized water) was used in the extractors. Extractors were equilibrated for a period of 5 days with soil suspensions. Total herbicide residue in soil was determined by a robotized $80 \%$ methanol extraction method at $22{ }^{\circ} \mathrm{C}$ [12]; and by its modification at $60{ }^{\circ} \mathrm{C}$ [13].

For anaerobic extractions, soils were incubated after adding $100 \mathrm{mg}$ of glucose to $10 \mathrm{~g}$ of soil suspended in $20 \mathrm{ml}$ deionized water in a $20 \times 150$ $\mathrm{mm}$ culture tube (Teflon lined caps). Incubations were carried out in triplicate at about $30{ }^{\circ} \mathrm{C}$ in an anaerobic glove box (Coy Laboratories ${ }^{1}$, Ann Arbor, $\mathrm{MI}$ ) in a $95 \% \mathrm{~N}_{2}: 5 \% \mathrm{H}_{2}$ atmosphere. Final

\footnotetext{
${ }^{1}$ Names are necessary to report factually on available data; however, the USDA neither guarantees nor warrants the standard of the product, and the use of the name by USDA implies no approval of the product to the exclusion of others that may also be suitable.
} 
A. Olness et al. / Talanta 57 (2002) 383-391

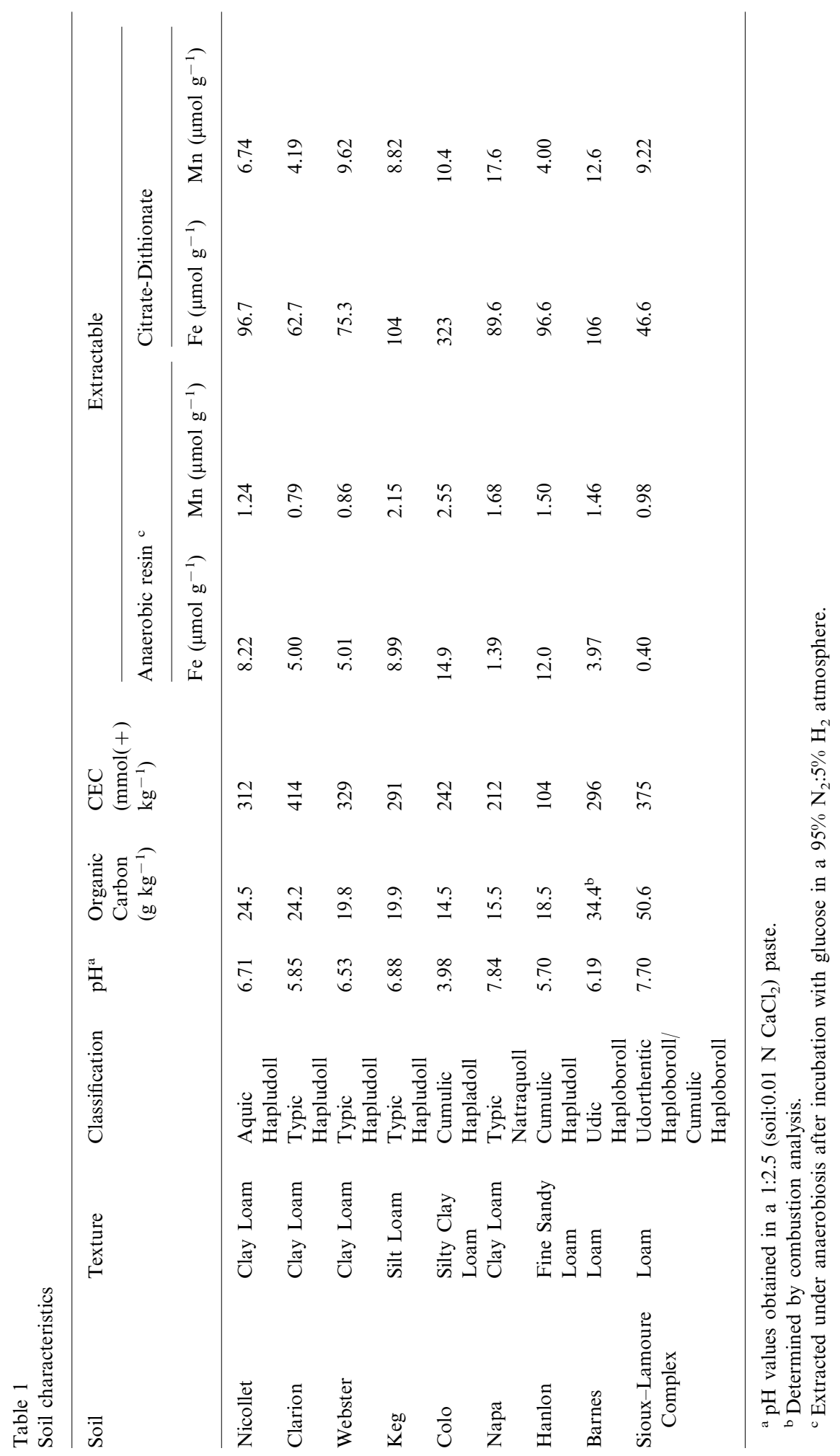



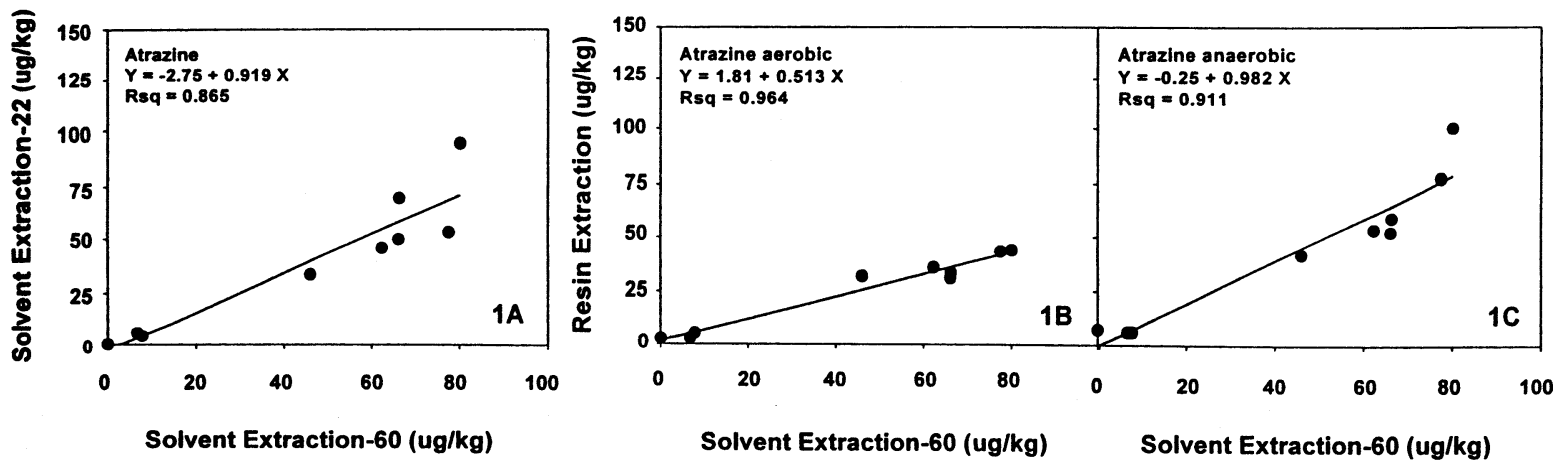

Fig. 1. Relative amounts of atrazine obtained with solid phase extractors and resin-extraction under aerobic and anaerobic conditions.

redox values were determined using a platinizedplatinum electrode. After redox potentials reached $\leq-150 \mathrm{mV}$ (adjusted for calomel potential), $5 \mathrm{ml}$ of methanol were added and a resin-extractor was inserted in each sample. Samples were placed on a reciprocating platform rocker and agitated continuously and slowly for 5 days after which they were removed, rinsed with $10 \mathrm{ml}$ deionized water and eluted with $10 \mathrm{ml}$ methanol. Extractors were vertically orientated during elution and methanol was introduced at the base (either by pump or by syringe at a rate of $2 \mathrm{ml} \mathrm{min}^{-1}$ ) and collected through a capillary Teflon tube inserted at the top of the extractors (this procedure avoids channeling due to air bubbles introduced into the extractors on preparation for elution). Eluate was evaporated to dryness, made up to $1.2 \mathrm{ml}$ with methanol and shaken on a platform rocker for $2 \mathrm{~h}$.

\subsection{Determination and confirmation of pesticides}

Dual-column gas chromatography was used for determination and confirmation of herbicides. Simultaneous determination of atrazine, alachlor and metribuzin was performed by a modified U.S. EPA Method $507[6,14]$. Retention times on the DB-5 column ${ }^{2}$ were $8.25,9.78$ and $10.0 \mathrm{~min}$ for

\footnotetext{
${ }^{2}$ Names are necessary to report factually on available data; however, the USDA neither guarantees nor warrants the standard of the product, and the use of the name by USDA implies no approval of the product to the exclusion of others that may also be suitable.
}

atrazine, metribuzin, and alachlor, respectively. Retention times on the DB-1701 column were 10.2, 12.3 and $12.9 \mathrm{~min}$ for atrazine, alachlor and metribuzin, respectively.

\subsection{Determination of extractable Fe and $\mathrm{Mn}$}

Citrate-dithionate (CD) extractable Fe and Mn were determined using the method of Ross and Wang [15]. Anaerobically extractable Fe and Mn were determined by incubating soil samples (6 g) in a glove box with a $95 \% \mathrm{~N}_{2}: 5 \% \mathrm{H}_{2}$ atmosphere with $6 \mathrm{ml}$ of $10 \%$ glucose and $42 \mathrm{ml}$ of deionized water in $50 \mathrm{ml}$ polycarbonate centrifuge tubes. After establishing anaerobiosis, tubes were sealed, centrifuged, returned to the anaerobic glove box, filtered through Whatman \# 42 filter paper, and supernatant extracts diluted $50 \mathrm{ml}$ in $0.1 \mathrm{~N} \mathrm{HCl}$. Concentrations of $\mathrm{Fe}$ and $\mathrm{Mn}$ were determined using standard atomic absorption spectrophotometry methods.

\subsection{Statistical analyses}

Data were analyzed using SAS PROC GLM and PROC REG procedures [16]. A probability level of 0.05 was used as the significance level.

\section{Results and discussion}

About $10 \%$ (atrazine) to $35 \%$ (metribuzin and alachlor) more herbicide was extracted with $80 \%$ 
methanol at $60{ }^{\circ} \mathrm{C}\left(\mathrm{SPE}_{60}\right)$ than extraction at $22{ }^{\circ} \mathrm{C}$ (SPE 22; $P<0.05$; Fig. 1AFig. 2AFig. 3A). Generally, a close relationship existed between the $\mathrm{SPE}_{22}$ and $\mathrm{SPE}_{60}$ for atrazine and metribuzin and a much weaker relationship existed for alachlor (Fig. 2BFig. 3B).

Aerobic RE provided slightly better correlation with $\mathrm{SPE}_{60}$ for metribuzin and atrazine extraction than did $\mathrm{SPE}_{22}$ (Fig. 1BFig. 2B). It consistently extracted about $40-50 \%$ of the metribuzin and atrazine, respectively, obtained with the $\mathrm{SPE}_{60}$ method. Like the $\mathrm{SPE}_{22}$ method, the aerobic RE of alachlor showed only a weak correlation with $\mathrm{SPE}_{60}$ method. Much of the difference between the $\mathrm{SPE}_{22}$ and the aerobic RE method occurred with the Colo soil. This soil is very acidic and contains relatively modest amounts of organic carbon.

Since large amounts of pesticides adsorbed on soils are in equilibrium with the soil solution [17], adding a 'clean' adsorptive surface such as XAD2 resin to a soil suspension imposes a chemical potential or gradient. This potential, or gradient leads to a redistribution of reversibly adsorbed pesticide or organic residues in proportion to the relative amounts of soil and resin surface. Reversibly adsorbed organic molecules detach from the soil surface and migrate to the new surface until a new equilibrium is approached. In this sense, resin-extracted amounts of pesticide should show closer correlation with herbicide efficacy in the field.

An important consequence of using resins to competitively adsorb herbicides from soil is that single extractions fail to remove $100 \%$ of the 'available' herbicide existing in equilibrium. In fact, even in the absence of a competing surface, the XAD-2 resin adsorbed only about $80-85 \%$ of the atrazine within 5 days when equilibrated at $22{ }^{\circ} \mathrm{C}$ [6]. If the same conditions hold for competitive removal from soil suspensions, then the results clearly suggest that SPE methods are not achieving complete recovery of 'aged' or bound residues during soil extractions. Also, the relative effectiveness of single REs depends on the sum of the surface of the soil and of the resin. Presumably, if one is known, the other can be determined from equilibria studies.

During reduction events, the dissolution of amorphous oxides of $\mathrm{Fe}$ and $\mathrm{Mn}$ is expected to expose additional adsorbed material for extraction. With this reduction comes a release of a variety of substances including organic matter which was been trapped within the oxide precipitates. Many soil analytical procedures have little effect on these amorphous oxides and thus may miss some of the xenobiotics present. By incubating the soil with glucose, an anaerobic environment can be developed rather quickly in the laboratory. By extracting the soils with resin ex-

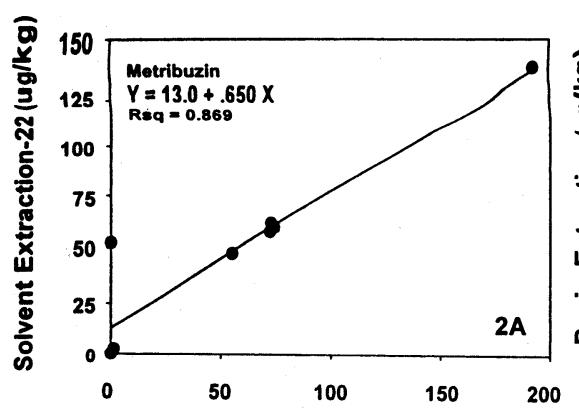

Solvent Extraction-60 (ug/kg)

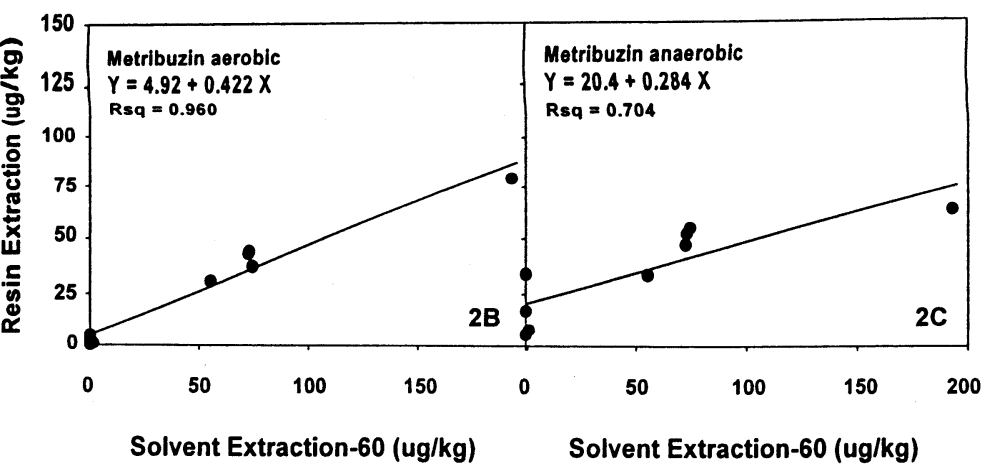

Solvent Extraction-60 (ug/kg)

Solvent Extraction-60 (ug/kg)

Fig. 2. Relative amounts of metribuzin obtained with solid phase extractors and resin-extraction under aerobic and anaerobic conditions. 


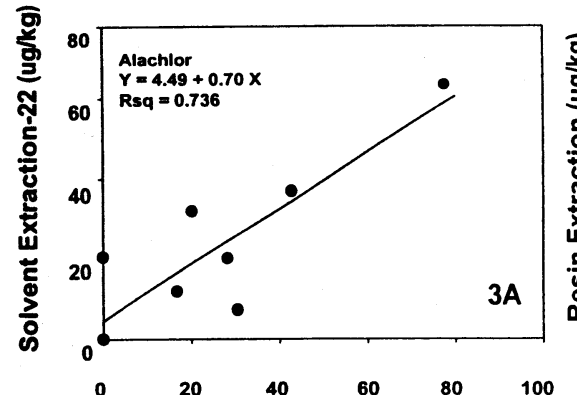

Solvent Extraction-60 (ug/kg)

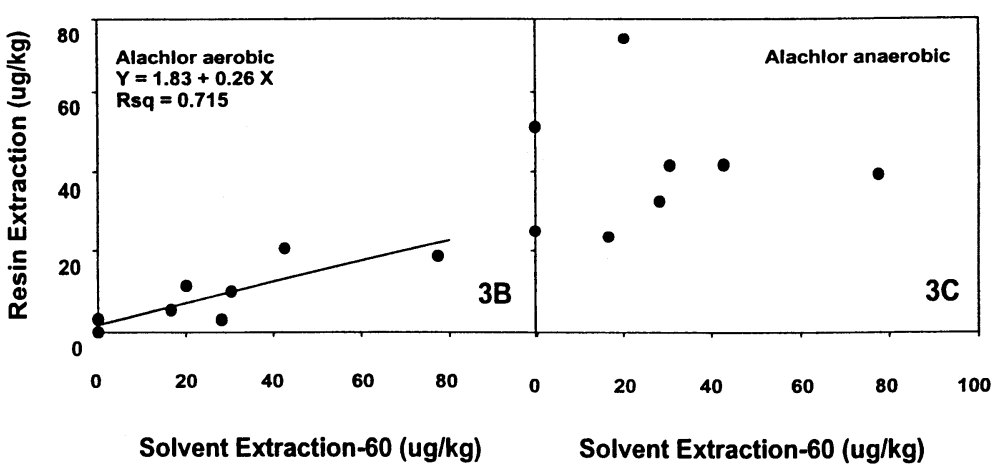

Fig. 3. Relative amounts of alachlor obtained with solid phase extractors and resin-extraction under aerobic and anaerobic conditions.

tractors under these conditions, the relative equilibria between soil adsorbed and resin adsorbed herbicide shifts.

When the soils were extracted under anaerobic conditions, RE methods recovered nearly twice as much atrazine relative to the oxidized environment $(P<0.05)$ and the correlation with $\mathrm{SPE}_{60}$ methods was quite close (Fig. 1B and C). The increase in atrazine recoveries with anaerobiosis was also closely correlated with total organic carbon $(P<0.01$; Fig. 4$)$; this is expected when the herbicide is adsorbed on the organic matter and subsequently occluded through redox events.

Atrazine is the least soluble (28 and $70 \mathrm{mg} \mathrm{1}^{-1}$ in water at 20 and $25{ }^{\circ} \mathrm{C}$, respectively; [18] and it has a partition coefficient for soil organic carbon, $K_{\text {oc }}$, of 100 [22]. This explains the rather close correlation between the increase in resin extractable atrazine and organic carbon, under anaerobic conditions. The rather close correlation $\left(R^{2}=0.911\right)$ and slope $(0.98)$ of the relationship between $\mathrm{SPE}_{60}$ and anaerobic RE suggests that $\mathrm{SPE}_{60}$ is effective at solubilizing some of the amorphous oxides and releasing/exposing more atrazine for extraction. Also, the resin surface is an effective competitor with the soil surfaces for adsorption of atrazine.

Many pesticides, including atrazine, form relatively unextractable 'bound residues' [19]. Conversion of readily extractable residues to a bound or 'aged' form is often observed with weathering under field conditions [20]. Here, pesticides had been applied to the soils a few years before they were extracted (samples were stored air-dried during the intervening period). The results suggest that these soils contain large amounts of 'aged' or bound pesticide residues. Evidently, heating in methanol solubilizes some bound atrazine fraction because atrazine extracted by $\mathrm{SPE}_{60}$, was, on average, greater than $\mathrm{SPE}_{22}$ (Fig. 1A).

If a field site previously treated with atrazine were to undergo anaerobiosis, we would expect a portion of the previously 'bound' residues to be released and become redistributed upon subsequent oxidation. Such a situation would lead to variable effects of herbicide 'carryover' or residual effects on crops grown in subsequent seasons. Current techniques are poorly suited to predicting such an environmental effect while RE will provide estimates of the potential relative effect.

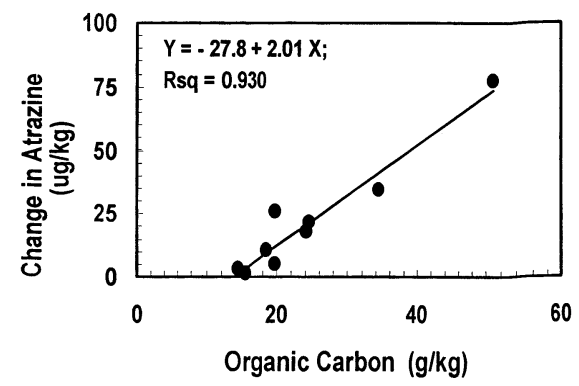

Fig. 4. The change in resin-extracted atrazine between aerobic and anaerobic extractions plotted as a function of soil organic matter. 
Anaerobic RE appeared more efficient only for the Sioux-Lamoure soil, which has a much greater organic C content. During the solutionextraction process, pesticides can become complexed with naturally occurring and soluble soil organic matter [21]. This could account for greater amounts of atrazine found in the SiouxLamoure soil using anaerobic RE. Gas chromatograms from aerobic extractions show very little evidence of co-extracted soil organic matter. In contrast, gas chromatograms from resinextractions conducted anaerobically show the presence of many unidentified materials. Co-extraction of herbicides with small soil organic molecules could subsequently be separated on the basis of temperature during the chromatography process.

Unlike atrazine, metribuzin recoveries varied with anaerobiosis (Fig. 2B and C). Metribuzin is about twenty times more soluble than atrazine $\left(1200 \mathrm{mg} 1^{-1}\right.$ at $20^{\circ} \mathrm{C}$ ) and it has a $K_{\text {oc }}$ of 60 [22]; thus, it is less likely to be co-precipitated with amorphous oxides than either atrazine or alachlor. However, only a fraction of the metribuzin in the Napa soil was recovered by RE while increases relative to the SPE methods were indicated from the Keg, Colo and SiouxLamoure soil.

The increases in metribuzin were generally small but some metribuzin was recovered from all soils whereas, SPE methods failed to detect metribuzin in three of the soils. The failure to extract as large a fraction of metribuzin as of atrazine with RE from several soils probably represents a volume of liquid effect. With SPE, the liquid volume is separated by centrifugation whereas only the dialysis membrane and the resin surface form the effective separator with RE. As the hydrophobicity decreases or the solubility increases, the efficiency of a competing organic surface decreases and this is consistent in the metribuzin and atrazine results. Comparison of aerobic and anaerobic RE results (Fig. $2 \mathrm{~B}$ and $\mathrm{C}$ ) suggests redox sensitive surfaces are less important in recovery of metribuzin than of atrazine.

Aerobic RE of alachlor correlated well with SPE extraction; however, RE obtained only a fraction of the apparent SPE recoveries of alachlor (Fig. 3B). The solubility of alachlor in water $\left(242 \mathrm{mg} 1^{-1}\right.$ at $\left.25^{\circ} \mathrm{C}\right)$ is intermediate to that of atrazine and metribuzin but it has the largest $K_{\mathrm{oc}}$ at 170 . However, relative to SPE, anaerobic RE recovery of alachlor was greater from all except the Colo soil $(P<0.05)$. Unlike atrazine and metribuzin, the anaerobic extraction showed virtually no relationship with the SPE or aerobic extraction methods. In one instance, neither SPE extraction at 22 or $60{ }^{\circ} \mathrm{C}$ detected the presence of alachlor but after anaerobic incubation, $25 \mu \mathrm{g} \mathrm{g}^{-1}$ were obtained with RE. The amounts of alachlor recovered after anaerobiosis were greater for all soils than with aerobic extraction; although, none of the concentrations recovered was very large. For example, $50 \mu \mathrm{g}$ $\mathrm{kg}^{-1}$ would only amount to about $100 \mathrm{~g} \mathrm{ha}^{-1}$ $0.15 \mathrm{~m}^{-1}$ and this would be about $10 \%$ of a typical annual application rate.

While the Colo soil contains at least $75 \mathrm{ng}$ of alachlor $\mathrm{g}^{-1}$, it seems much more tightly held by the soil. Since the RE procedure is adsorbing alachlor from solution, the difference between the amounts of alachlor obtained by RE and $\mathrm{SPE}_{60}$ amounts suggests that alachlor, applied at similar rates, would be less effective in weed control on this soil than on several of the other soils examined. Also, with greater binding to the soil (slow release) we expect release of this pesticide into the soil solution over a longer period of time. The latter effect could be a complicating factor in crop rotation sequences.

The addition of glucose is unlikely to effect significant release from soil of any the herbicides presented here. Glucose is a much more soluble compound than the three herbicides and a poor competitor for adsorption sites. Also, it appears unlikely that microbial degradation of any of the herbicides was greatly affected by the incubation with glucose; Seybold et al. [23] have shown losses of less than $5 \%$ of freshly added atrazine or metolachlor during 7 days incubation at $24{ }^{\circ} \mathrm{C}$. Here anaerobiosis was achieved in $\leq 2$ days and then microbial activity was inhibited by the addition of methanol $(20 \%)$.

Since a single RE is incomplete, the amounts of extractable herbicides detected after anaero- 
biosis are undoubtedly greater than those obtained with $\mathrm{SPE}_{60}$ methods. Also, no corrections were made in the current study for recovery efficiency of the herbicides from the resins after equilibration as noted by Basta and Olness [6]. As a consequence, it is probable that current methods of soil analysis are underestimating the residual amounts of herbicides in soils.

\subsection{Fe and $\mathrm{Mn}$}

Each of the soils contained rather large amounts of extractable $\mathrm{Fe}$ and $\mathrm{Mn}$ (Table 1). The amounts of $\mathrm{Fe}$ and $\mathrm{Mn}$ extractable under anaerobic conditions are 100 to $>1000$ times the usual amounts extractable with water under aerobic conditions (data not shown). While these are only two of several chemical species sensitive to redox potential, $\mathrm{Fe}$ and $\mathrm{Mn}$ are present in greater amounts and they are expected to directly interact with organic compounds upon oxidation because they tend to precipitate on stable surfaces as amorphous oxide coatings. The application times and amounts and the climatic conditions both before and after application are only vaguely known so correlations of extractable herbicides with extractable $\mathrm{Fe}$ and $\mathrm{Mn}$ are of questionable value. Controlled laboratory studies are required to determine redox effects on rate of pesticide adsorption, post adsorption occlusion, and 'decay' or inactivation.

Bound residues are associated with humic and clay fractions of the soil [24,25]. Apparently, when microbial activity creates anaerobic conditions, some bound atrazine is released. Also, less atrazine is adsorbed after removal of CD extractable $\mathrm{Al}$ and $\mathrm{Fe}$ from soil [26] and this suggests that $\mathrm{Fe}$ oxide sites affect adsorption of atrazine. Under microbially induced anaerobic conditions, redox sensitive amorphous $\mathrm{Fe}$ becomes solubilized and releases atrazine. Release of atrazine through reduction is consistent with the observation of Khan and Ivanson [27] who found bound prometryn was released by microbial activity. A similar effect would account for increased RE of atrazine under anaerobic conditions (Fig. 1C).
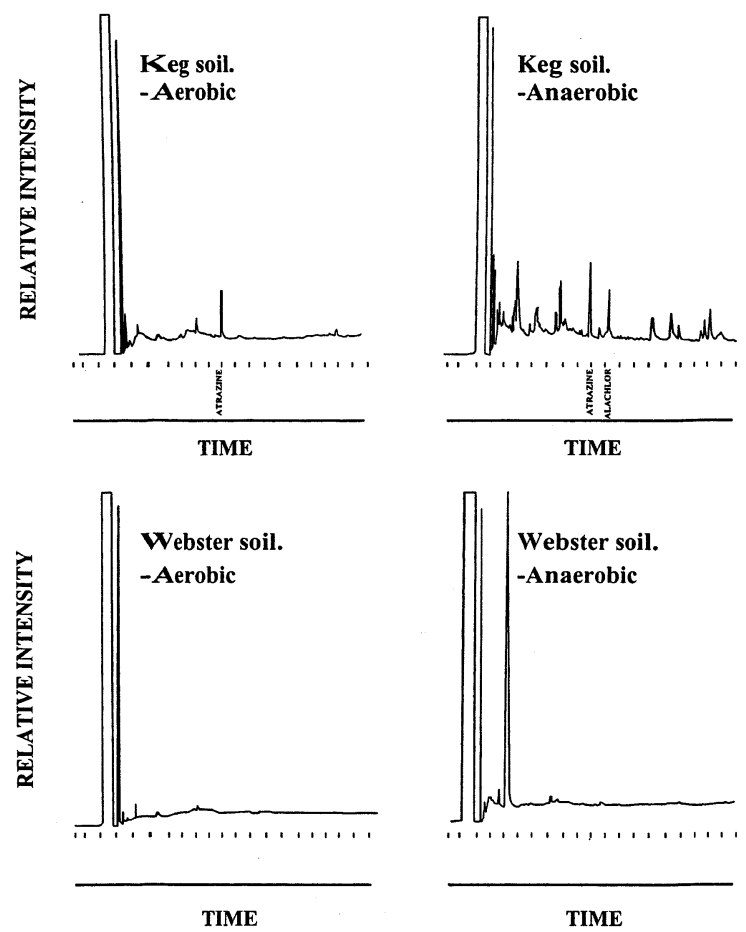

Fig. 5. Chromatograms of aerobically and anaerobically resinextracted residues from Keg and Webster soils. Chromatograms were obtained using a DB-1701 capillary column.

\subsection{Humic substances and other soil organic matter}

Relative amounts of other organic substances extracted varied considerably between soils and were also affected by oxidation status (Fig. 5). For example, anaerobic extraction of the Keg soil shows a large number of low molecular weight substances were extracted, while the same conditions for the Webster soil show rather small amounts of additional substances were extracted (Fig. 5). If retention of pesticides in soil is affected by soluble organic matter, then some differences in mobility of the pesticides within a soil should be reflected by the amounts of potentially mobilized organic matter. Water soluble, low molecular weight humic substances increase atrazine mobility in soils under field conditions [21]. 


\section{Summary and conclusions}

$\mathrm{RE}$ of atrazine and metribuzin from soil is closely correlated to SPE methods. The RE procedure enabled simultaneous extraction of atrazine, metribuzin and alachlor under anaerobic conditions. Amounts of alachlor extracted under anaerobic conditions was greater than the aerobic SPE methods; this suggests that amorphous $\mathrm{Fe}$ - and Mn-oxides protect or shield some herbicides from extraction under aerobic conditions. Increases in amounts of both extracted organic matter and pesticides under anaerobic conditions show the importance of redox sensitive oxides and environmental conditions on the release (and efficacy?) of pesticides. For atrazine, the RE coefficient (relative to $\mathrm{SE}_{60}$ values) increased with anaerobiosis to 0.98 . This is a large increase in the fraction of pesticide recovered with the extractor.

Redox conditions should have a marked effect on relative mobility of some pesticides and this mobility will vary between soils. Effects of redox potential and soluble organic matter are not readily reflected in conventional extraction methods but equilibrium RE appears to offer a promising technique in evaluation this aspect of soil chemistry.

\section{Acknowledgements}

The authors thank Dr T.J. Lemme for analytical determinations of the pesticides.

\section{References}

[1] USDA-ESS. usda.mannlib.cornell.edu/reports/nassr/ other/pcu-bb/agcs0501.txt. 2001.

[2] E.W. Pickering, P.L.M. Veneman, J. Environ. Qual. 48 (1984) 113-502.

[3] A. Olness, J. Rinke, H-M. Hung, S.D. Evans, 148 (1989) 265-274.

[4] A. Olness, J.A. Staricka, J.A. Daniel, G.R. Benoit, J.L. Rinke, J. Minn. Acad. Sci. 59 (1995) 35-40.
[5] R.J. Reuter, J.C. Bell, Soil Sci. Soc. Am. J. 65 (2001) 1559-1569.

[6] N.T. Basta, A. Olness, J. Environ. Qual. 21 (1992) 497.

[7] L.J. Mebius, Anal. Chim. 22 (1960) 120.

[8] J.C. Yeomans, J.M. Bremner, Commun. Soil Sci. Plant Anal. 19 (1988) 1467-1476.

[9] V.J. Kilmer, L.T. Alexander, Soil Sci. 68 (1949) 15-24.

[10] N.F. Walters, G.R. Hallberg, T.E. Fenton, in: G.R. Hallberg, (Ed.), Standard Procedures for Evaluation of Quaternary Materials in Iowa, Iowa Geol. Surv. Tech. Info. Series, 8 (1978) 61-90.

[11] J.D. Rhoades, in A.L. Page, R.H. Miller, D.R. Keeney, (Eds), Agron. Monograph 9. Methods of Soil Analysis Part 2. Chemical and Microbiological Properties. Am. Soc. Agron. 1982, pp. 149-157.

[12] W.C. Koskinen, L.J. Jarvis, R.H. Dowdy, D.L. Wyse, D.D. Buhler, Soil Sci. Soc. Am. J. 55 (1991) 561-562.

[13] L.Q. Huang, J.J. Pignatello, J. Assoc. Off. Anal. Chem. 73 (1990) 443-446.

[14] R.L. Graves, Method 507. Environmental Monitoring Systems Lab. USEPA \# 600488-039. Offices of Research and Development, USEPA, Cincinnati, OH. (1989).

[15] G.J. Ross, C. Wang, in: Soil Sampling and Methods of Analysis M.R. Carter, (Ed). Can. J. Soil Sci. Ottowa, Ontario, Canada. 1993, pp. 239-241.

[16] SAS Institute Inc. SAS/STAT User's Guide, Version 6, Fourth Ed., Vol. 2. SAS Institute, Cary, NC, 1989, pp. 846.

[17] W.C. Koskinen, S.S. Harper, in: H.H. Cheng, (Ed), Pesticides in the Soil Environment: Processes, Impacts, and Modeling. Soil Sci. Am., Madison, WI. 1992, pp. 51-78.

[18] B. pande, The Merck Index, in: M. Windholz, S. Budavari, R. Blumetti, E.S. Otterbein (Eds.), An Encyclopedia of Chemicals, Drugs and Biologicals, Merck \& Co, Rahway, NJ, 1983.

[19] S.U. Khan, Res. Rev. 84 (1982) 1-25.

[20] A.E. Smith, Can. J. Soil Sci. 62 (1982) 433-460.

[21] I. Scheunert, M. Mansour, Int. J. Environ. Anal. Chem. 46 (1992) 189-199.

[22] R.D. Wauchope, T.M. Buttler, A.G. Hornsby, P.W.M. Augustijn-Beckers, J.P. Burt, Rev. Environ. Contam. Toxicol. 123 (1992) 1-164.

[23] C.A. Seybold, W. Mersie, C. McNamee, J. Environ. Qual. 30 (2001) 1271-1277.

[24] P. Capriel, A. Haisch, S.U. Khan, J. Agric. Food Chem. 33 (1985) 567-569.

[25] A. Calderbank, Rev. Environ. Contam. Toxicol. 108 (1989) 71-103.

[26] L.Q. Huang, R. Grover, R.B. McKercher, Soil Sci. 138 (1984) 20-24.

[27] S.U. Khan, K.C. Ivanson, J. Agric. Food Chem. 29 (1981) 1301-1303. 